\title{
COVID-19 and Containment: A Dual Burden for India
}

\section{Nathan John Grills ${ }^{\mathrm{a}}$}

\author{
${ }^{a}$ MBBS, MPH, DPhil, Associate Professor, Nossal Institute for Global Health, University of Melbourne; Senior Research \\ Advisor, Australia India Institute
}

\begin{abstract}
Could ongoing COVID-19 'lockdowns' in India risk more harm than the pandemic itself given a population already facing major poverty and health challenges?
\end{abstract}

Key Words: India, COVID-19, mitigation, containment, lockdown, poverty, economy, public health.

Was India's strategy of imposing a sudden total lockdown in response to COVID-19 really needed? And, could an ongoing lockdown actually threaten more lives than the coronavirus itself? Late last month, Prime Minister Narendra Modi announced a 21-day complete lockdown of the country's 1.3 billion people. ${ }^{1}$ But, is this too much too soon? Given the relatively small number of cases in the country at the time of the sudden announcement - less than a 1000 — there was certainly scope to delay the timing to allow people to prepare. For example, a week's warning could have given time for the millions of migrant labourers to return home. ${ }^{2}$

We also need to consider what the lockdown is supposed to achieve and whether it is achievable. Realistically, trying to suppress or eliminate COVID19 in India would appear to be a pipe dream given the mass overcrowding, porous borders, and large-scale migratory labour patterns. And even if suppression could be achieved until a vaccine is developed, it's difficult to imagine a timely vaccine roll out across a nation of the scale and complexity of India.

So, the purpose of the lockdown should almost certainly be mitigation, and if that is the case, then at this early stage a more moderate approach would appear to have been justifiable. Any decision on what strategy to adopt firstly needs to be informed by an assessment of the risk COVID-19 poses in India. India has a median age of 28 years old, which will be protective, to some degree, given the low case fatality rate (CFR) at young ages.
We know that the average age of death in Italy from COVID-19 has been around 79, whereas India's average life expectancy is just 68 years of age. ${ }^{3}$ Most COVID-19 deaths have been in the elderly, and the risk of death when aged below 50 is smaller and nearly unheard of below 18 years old. These age factors will help protect India, but given its huge population, the total number of deaths could still be massive.

In assessing the risk, we can start by mapping the case fatality rate (CFR) rates from China onto the age demographics in India. We may actually expect lower CFRs given that India has had time to adapt, and we now know how best to approach management and prevention. In the early days of the epidemic in Wuhan, not much was known about COVID-19, which probably resulted in higher CFRs than might be expected in India. ${ }^{4}$ If we assumed that at least around 50 to 60 per cent of Indians would be infected before herd immunity could control the outbreak, and if we assume the same aged adjusted CFRs as China, then we are talking about a toll of 2.37 million deaths in India. Of these, 2.22 million (or 94\%) would be over 50 years of age. The young age of India's population will provide some protection from COVID-19 but the sheer size of the population means massive numbers will still be at serious risk. This is obviously a humanitarian catastrophe and represents a death rate, mostly made up of the elderly, of 0.17 per cent of the population. That is about the same number that die in India each year from tobacco and air pollution combined. ${ }^{5}$ 
Clearly then, serious action needs to be taken; but, there are many unknowns in imposing complete and long-term lockdowns. For example, if the pandemic is inevitable in India, we don't really know what proportion of these potential deaths can be prevented by a strict and long-running lockdown. Presumably, many deaths can be avoided by decreasing the stress on the health system. However, in India, the public health system is chronically overloaded and has little reserve, which means even a flattened curve to the infection rate will overwhelm the system and lead to many deaths. ${ }^{6}$

On the other side of the equation, the important question is how many Indians might die due in a strategy of long-term containment, lockdowns, and resultant economic collapse? Multidimensional poverty already affects 374 million Indians, and even without the social or economic impacts of an ongoing lockdown, 38 per cent of children under five are already stunted, 59 per cent are anaemic, and 21 per cent are wasted (thin for their height). ${ }^{7,8}$ A lockdown makes these groups even more vulnerable and will increase mortality rates.

Already, the severe effects of the lockdown are being documented across India with many millions of informal sector workers and daily wage labourers not covered by contracts and protections - facing destitution and hunger. ${ }^{9,10}$ These labourers are already food insecure and rely on daily wages for sustenance, to afford basic healthcare, and educate their children. Containment will have a very real cost in terms of lives. At the same time, the lockdown has meant that basic services and many health facilities have either closed or their services have been drastically reduced. ${ }^{11}$ I work in community health and disability in rural North India, and our program staff have reported villagers ringing up desperate to get their basic medicines. However, supply lines are cut, their local health facility is closed, and our staff are prevented from travel. Again, this will cost lives.

To gain a relative understanding of the magnitude of the impact of COVID-19, we can look at the impact on Disability Adjusted Life Years (DALY). ${ }^{12}$ Child and maternal malnutrition, and its resultant myriad of short and long term health problems, is by far the leading cause of lost DALYs in India at 83 million annually, and we can assume this will be exacerbated significantly by the hardships imposed by a lockdown strategy. ${ }^{13}$
In comparison, COVID-19 may cause the loss of 17 million DALYs if we assume that every person who dies loses an average of 7.5 DALYs, given that deaths tend to occur in the elderly and those with underlying illnesses. What we do know is that in India and in the US, more children will die from suppression, mitigation, lockdowns, and the economic downturn than from COVID-19 virus. Primary health facilities have either closed, or their services have been drastically reduced.

This raises an ethical question as to the "rightness" of employing draconian interventions that likely increase childhood mortality in order to decrease mortality largely in the elderly. To undertake any legitimate cost/benefit analysis, we would need much better data standardised for age on both the numbers of deaths from COVID-19 and deaths caused by lockdowns and the economic downturn.

The current policy mantra in India is seemingly to stop COVID-19 at all costs. But an "at all costs" approach is reckless. Following this 21-day lockdown, and prior to further lockdowns, serious consideration of the cost-benefit of different levels of mitigation strategies is required. There needs to be a dispassionate discussion about how much cost we are prepared to pay and for what gain?

\section{References}

1. Vaidyanathan R. Coronavirus: India enters 'total lockdown' after spike in cases [Internet]. BBC. 2020 Mar 25. Available from: https://www.bbc.com/news/world-asia-india$\underline{52024239}$

2. Frayer L, Pathak S. Coronavirus lockdown sends migrant workers on a long and risky trip home [Internet]. NPR. 2020 Mar 31. Available from: https:/www.npr.org/sections/goatsandsoda/2020/03/3 1/822642382/coronavirus-lockdown-sends-migrantworkers-on-a-long-and-risky-trip-home

3. Onder G, Rezza G. Case-fatality rate and characteristics of patients dying in relation to COV19 in Italy. JAMA Network. 2020 Mar 23. http://dx.doi.org/10.1001/jama.2020.4683

4. McDonell S. Coronavirus: China says disease 'curbed' in Wuhan and Hubei [Internet]. BBC. 2020 Mar 10. Available from:

https://www.bbc.com/news/world-asia-china51813876

5. Singh K. Air pollution is a bigger killer than tobacco use in India [Internet]. Quartz India. 2020 Apr 2. Available from: 
https://qz.com/india/1585690/air-pollution-is-abigger-killer-than-tobacco-use-in-india/

6. Sharma S. India's public health system in crisis: too many patients, not enough doctors [Internet]. Hindustantimes. 2017 Aug 29. Available from: https://www.hindustantimes.com/india-news/publichealth-system-in-crisis-too-many-patients-notenough-doctors/story39XAtFSWGfO0e4qRKcd8fO.html

7. Multidimensional Poverty Index, 2019, table 1 [Internet]. Available from: http://hdr.undp.org/sites/default/files/mpi_2019_pub lication.pdf

8. India National Family Health Survey. 2017 Dec. Government of India Ministry of Health and Family Welfare. p 291, 293.

9. Abi-Habib M, Yasir S. For India's laborers, Coronavirus lockdown is an order to starve [Internet]. The New York Times. 2020 Mar 30. Available from: https://www.nytimes.com/2020/03/30/world/asia/cor onavirus-india-lockdown.html

10. Jeffrey C, De Geest F, Dyson J. 'How will we eat'?
India's coronavirus lockdown threatens millions with severe hardship [Internet]. The Conversation. 2020 Mar 30. Available from:

https://theconversation.com/how-will-we-eat-indiascoronavirus-lockdown-threatens-millions-withsevere-hardship-135193

11. Goli S. Coronavirus: the lockdown and its consequences [Internet]. Deccan Herald. 2020 Apr 20. Available from:

https://www.deccanherald.com/opinion/coronavirusthe-lockdown-and-its-consequences-820261.html

12. World Health Organization. Metrics: disabilityadjusted life year (DALY) [Internet]. n.d. Available from:

https://www.who.int/healthinfo/global_burden_disea se/metrics daly/en/

13. Nie P, Rammohan A, Gwozdz W, Sousa-Poza A. Changes in child nutrition in India: a decomposition approach. 2019. Int J Environ Res Public Health. 16:1815. Available from: https://www.ncbi.nlm.nih.gov/pmc/articles/PMC657 $\underline{2133 /}$

Competing Interests: None declared.

Acknowledgements: First published with Health \& Well-being 6 April 2020, and co-published with the Australia India Institute. https://pursuit.unimelb.edu.au/articles/covid-19-andcontainment-a-dual-burden-for-india

Correspondence: Nathan Grills, Melbourne, Australia.ngrills@unimelb.edu.au

Cite this article as: Grills NJ. COVID-19 and Containment: A Dual Burden for India. Christian Journal for Global Health. April 2020; 7(1):24-26. https://doi.org/10.15566/cigh.v7i1.377

(C) Author. This is an open-access article distributed under the terms of the Creative Commons Attribution License, which permits unrestricted use, distribution, and reproduction in any medium, provided the original author and source are properly cited. To view a copy of the license, visit http://creativecommons.org/licenses/by/4.0/ 